\title{
EXPERIMENTAL TESTS ON ROLLING RESISTANCE OF ROAD WHEELS IN RUBBER TRACKED UNDERCARRIAGES
}

\author{
P. Dudziński", J. Chołodowski ${ }^{* *}$, M. Ketting ${ }^{* * *}$
}

\begin{abstract}
Double flange road wheels are often applied in undercarriages with rubber tracks and belts because of numerous advantages. Research on energy efficiency of rubber track systems conducted by the Department of Off-Road Machine and Vehicle Engineering (Wroctaw University of Science and Technology) indicates that the amount of energy lost due to interaction between double flange roller and rubber track or belt is influenced by contact pressure distribution between the roller and the track. In order to minimize motion resistance of the rollers, the pressure distribution should be possibly uniform, which has been shown in the following article on the basis of experiments. Consequently, it might be concluded that application of suspension systems enabling double flange rollers to oscillate in transverse vehicle plane might contribute to an increase in energy efficiency of undercarriages with rubber tracks and belts.
\end{abstract}

Keywords: energy efficiency, track crawler, rubber track, road wheel, double flange roller

\section{Introduction}

Double flange rollers are applied in undercarriages with rubber tracks and belts mainly to maintain uniform pressure distribution between the track and the ground in transverse vehicle plane. In such conditions high traction forces can be effectively transmitted and the tread of the tracks is prevented from nonuniform wear. However, so as to uniformly distribute the weight of the vehicle on the entire area of the track contact patch, vertical load of each roller must be equally divided between both of its flanges. In practice, if a tracked vehicle with double flange rollers negotiates uneven terrain or operates on a slope

a)

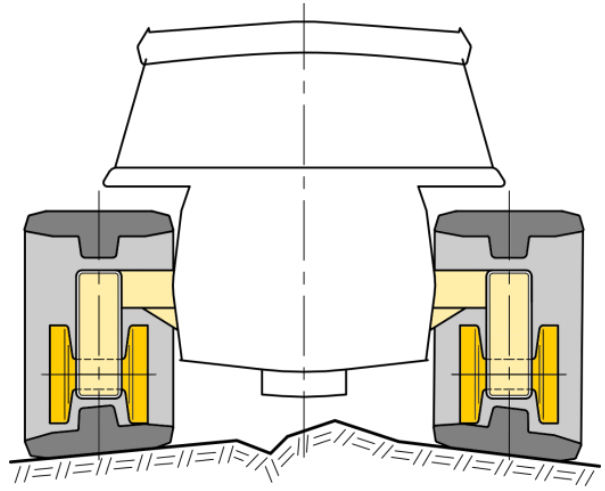

b)

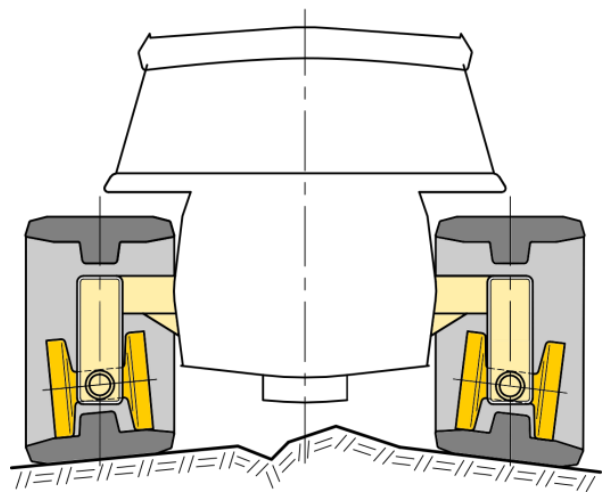

Fig. 1: Tracked vehicle with rubber belt standing on uneven ground a) vehicle having non-oscillating double flange rollers, $b$ ) vehicle having suspension system with oscillating double flange rollers

Prof. Dr. habil. Eng. Piotr A. Dudziński: Department of Off-Road Machine and Vehicle Engineering, Wrocław University of Science and Technology, ul. Łukasiewicza 7/9; 50-371, Wrocław; PL, piotr.dudzinski@pwr.edu.pl

** M.Sc. Eng. Jakub Chołodowski: Department of Off-Road Machine and Vehicle Engineering, Wrocław University of Science and Technology, ul. Łukasiewicza 7/9; 50-371, Wrocław; PL, jakub.cholodowski@pwr.edu.pl

*** Prof. Dr. Michael Ketting: IBAF-Institut für Baumaschinen, Antriebs- und Fördertechnik GmbH Bochum RuhrUniversität Bochum; Germany, M.Ketting@ibaf-bochum.de 
inclined in lateral vehicle plane, at least several flanges of its rollers are not supported by the track (Fig. 1a.). Some machinery manufacturers try to solve this problem by implementing suspension systems with oscillating double flange rollers (Fig. 1b.) (Camso, 2018, Roth, 2004 and Rosenboom, 2008).

The Department of Off-Road Machine and Vehicle Engineering (DORMVE, Wrocław University of Science and Technology) spends a lot of effort on research and development of undercarriages with rubber tracks and belts. The scope of DORMVE study includes development of innovative technical solutions and design methods (Dudziński, Ketting, 1996 and Dudziński et al., 2003), identification of external (Dudziński, Stefanow, 2016 and Dudziński, Gładysiewicz, 2007) and internal motion resistance (Dudziński, Chołodowski, 2016 and Dudziński, Chołodowski, 2017) as well as virtual tests and safety issues (Dudziński et al., 2012 and Kosiara, Stefanow, 2017). Basing on currently conducted research, the authors of the following paper conceived a hypothesis that uniform contact pressure distribution between double flange roller and rubber track results in the smallest possible rolling resistance (Dudziński, Chołodowski, 2016). The thesis has been verified by experiments presented herein.

\section{Materials and methods}

Research on motion resistance of exemplary double flange roller was carried out using the test stand depicted in Fig. 2. The key part of the stand is a plate for measuring vertical, longitudinal and lateral force acting on the roller while rolling over rubber track fixed to the upper surface of the plate. The plate is designed in such a way that the angle between track inner surface and roller's axis of rotation (roller tilt angle $\alpha$ ) might be easily adjusted. The roller is loaded in vertical direction with an arm of the test stand and additional weights optionally attached to the arm. Motion resistance coefficient $f$ is calculated after each trial according to eq. (1), based on mean rolling resistance force $F_{R}$ and average vertical load $G$.

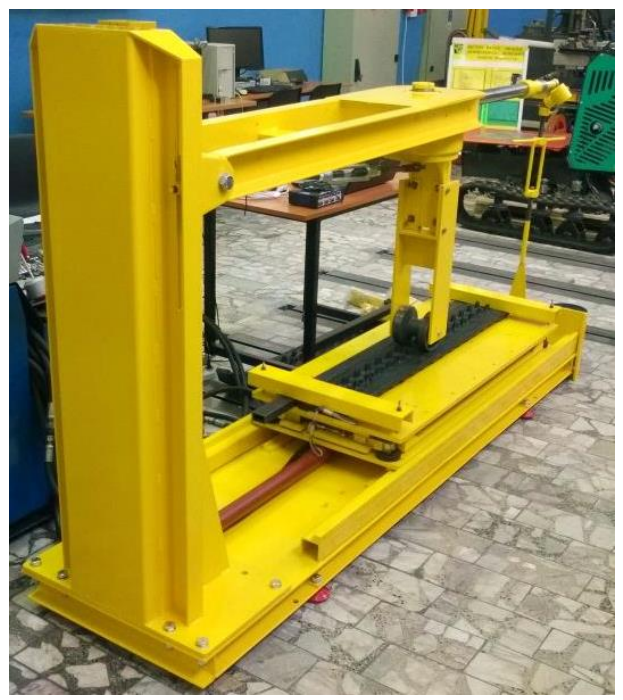

$$
f=\frac{F_{R}}{G}
$$

Fig. 2: Test stand for determination of motion resistance of road wheels rolling over rubber track in laboratory of DORMVE at Wroctaw University of Science and Technology

\section{Test results}

The stated hypothesis was verified using exemplary $140 \mathrm{~mm}$ diameter, steel, double flange roller and $180 \mathrm{~mm}$ wide rubber track with steel stiffening transverse inserts. The pitch of the track was $72 \mathrm{~mm}$.

Two empirical relationships $(2,3)$ between vertical load and motion resistance coefficient of the roller under consideration at uniform roller-track contact pressure distribution (i.e. roller tilt angle $\alpha=0^{\circ}$ ) have already been determined in (Dudziński, Chołodowski, 2017). Equation (2) represents "pure rolling" case, where roller did not touch guide lugs while rolling over the track, whereas eq. (3) was fitted to results of tests carried out in the case where roller was sliding over guide lugs.

$$
f=0.0034 G^{0.35}
$$




$$
\hat{f}=0.843 G^{-0.30}
$$

Relationships $(2,3)$ as well as motion resistance coefficient values determined herein at roller tilt angles $\alpha_{1}=3^{\mathrm{O}}$ and $\alpha_{2}=7^{\mathrm{O}}$ and different loads are depicted in Fig. 3. During the tests carried out in actual research roller did not touch guide lugs of the track.

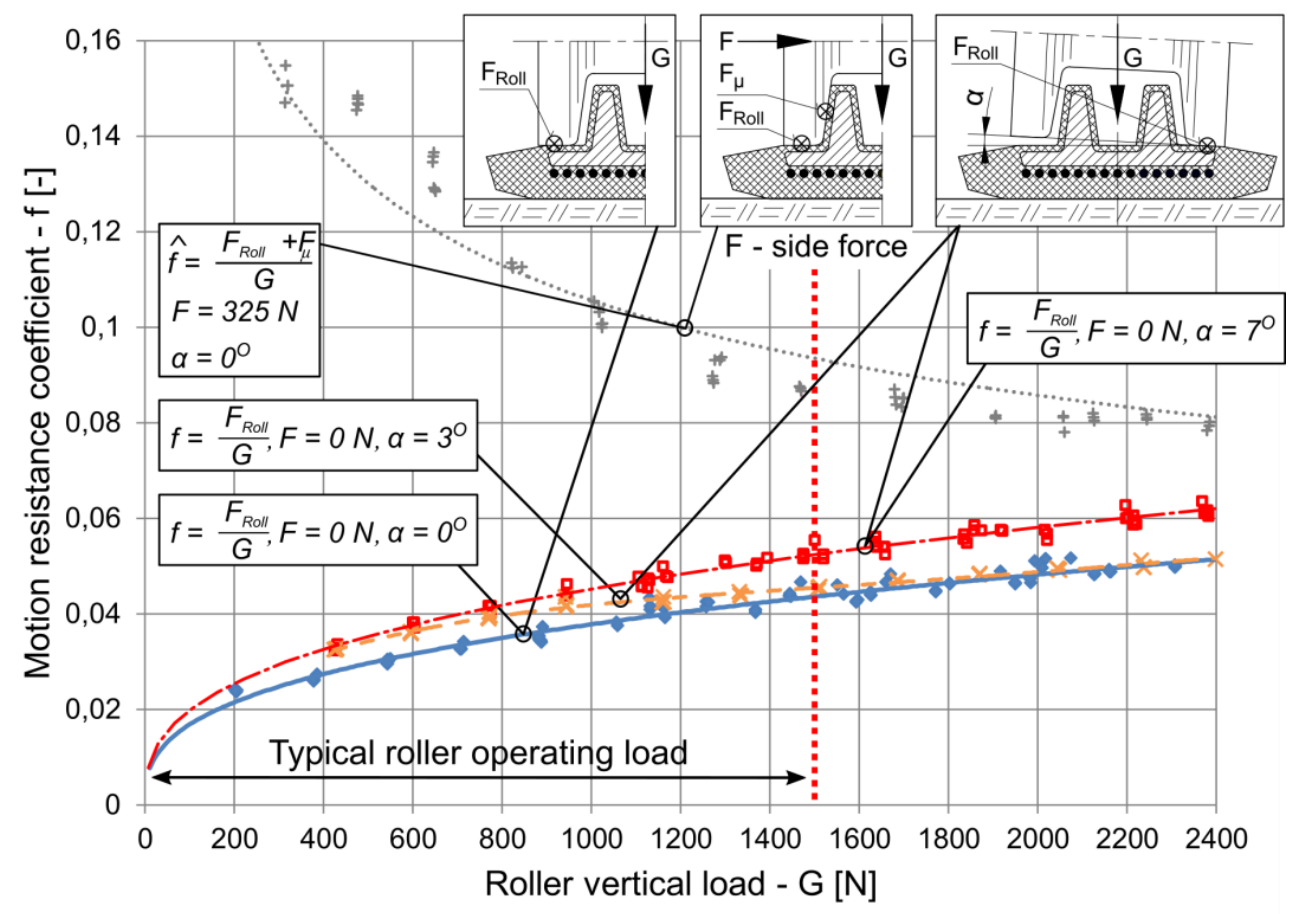

Fig. 3: Relationship between motion resistance coefficient and vertical load determined for exemplary steel, double flange roller and rubber track in different load cases

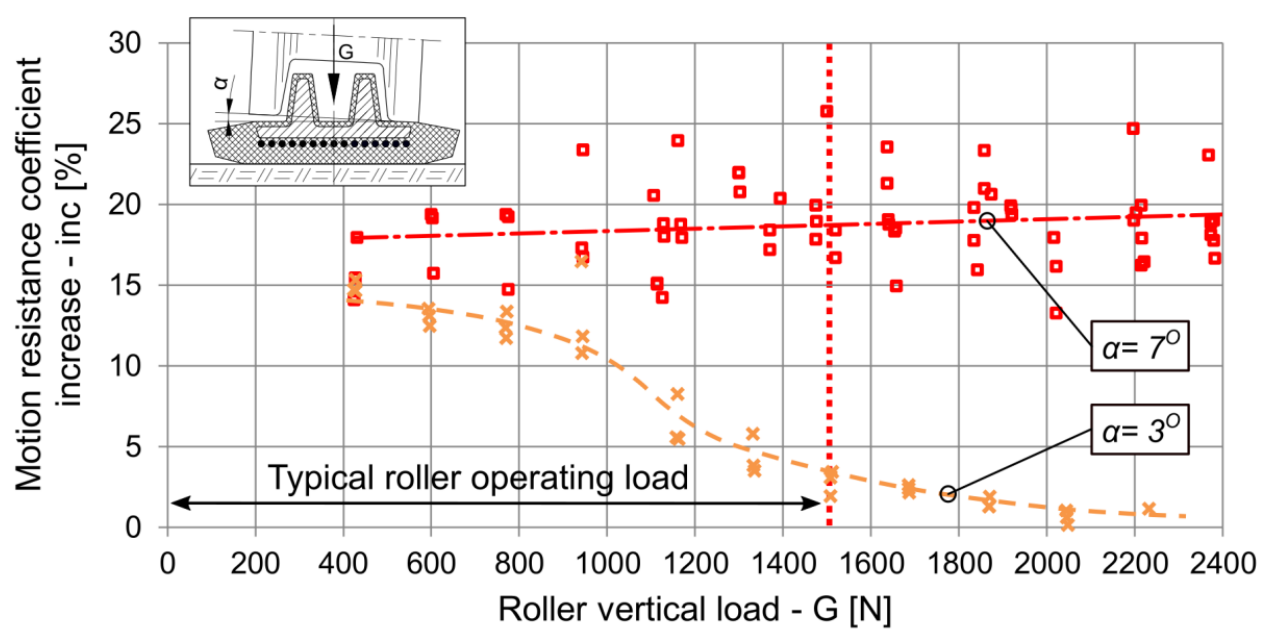

Fig. 4: Incerease in motion resistance coefficient caused by non-uniform pressure distribution in double flange roller-rubber track contact as a function of overall roller vertical load

Rolling resistance coefficient values noted at both non-zero tilt angles were generally higher than ones determined in uniform roller-track contact pressure conditions. On the other hand, they are far smaller than respective values measured in load case where sliding friction between roller and track guide lugs occurs. Figure 4. reproduces increase in motion resistance coefficient due to non-uniformity in rollertrack contact pressure calculated using eq. (4).

$$
\operatorname{inc}\left(G_{i}\right)=\frac{f_{\text {non-uni }}\left(G_{i}\right)-f_{\text {uni }}\left(G_{i}\right)}{f_{\text {uni }}\left(G_{i}\right)} \cdot 100 \%
$$

- $f_{\text {non-uni }}\left(G_{i}\right)$ - rolling resistance coefficient measured at specified roller vertical load $G_{i}$ and nonzero roller tilt angle (i.e. at non-uniform contact pressure distribution), 
- $f_{u n i}\left(G_{i}\right)$ - rolling resistance coefficient measured at specified roller vertical load and zero roller tilt angle (i.e. at uniform contact pressure distribution).

In comparison with uniform roller-track contact pressure conditions, rolling resistance at roller tilt angle $\alpha_{2}=7^{\circ}$ was higher by $15 \% \ldots 25 \%$ regardless of applied vertical load. In contrast, the increase in rolling resistance at tilt angle $\alpha_{l}=3^{\mathrm{O}}$ depended on roller load. At loads smaller than $800 \mathrm{~N}$, rolling resistance coefficient exceeded respective values determined at uniform roller-track contact pressure by $12 \% \ldots 15 \%$. On the other hand, at loads higher than $800 \mathrm{~N}$ rolling resistance coefficient values become closer to those measured at zero roller tilt angle.

Referring to the course of the experiment, at roller tilt angle $\alpha_{2}=7^{\mathrm{O}}$ vertical load of the roller was carried by only one roller's flange at all considered vertical loads. The second flange did not touch the track. Similar situation was encountered at tilt angle $\alpha_{1}=3^{\mathrm{O}}$ and vertical loads $0 \mathrm{~N} \ldots 800 \mathrm{~N}$. However, at $\alpha_{I}=3^{\mathrm{O}}$ and vertical loads exceeding $800 \mathrm{~N}$ vertical load was split between both roller's flanges, since both of them touched track surface.

\section{Conclusions}

The research discussed in the paper confirms that non-uniform contact pressure distribution between double flange roller and rubber track results in an increase in roller motion resistance coefficient. In comparison with rolling resistance coefficient determined at uniform pressure distribution, experiments described herein revealed an increase by up to $25 \%$. It is less than the increase due to sliding friction between roller and track guide lugs. However, the highlighted phenomenon should be taken into account while estimating power consumption of undercarriages with rubber tracks and belts.

The increase in roller rolling resistance caused by non-uniform roller-track contact pressure is exceptionally high when roller vertical load is carried by only one roller's flange. Hence, application of suspension systems with oscillating double flange rollers (Fig. 1b.), as well as any other remedies preventing flanges of rollers from losing contact with track, may improve energy efficiency of rubber tracked undercarriages.

Summarizing the research on rolling resistance of double flange rollers carried out by the authors, overall motion resistance coefficient of considered type of rollers, which is reasonable for design purposes, may be estimated by value $0.103 \ldots 0.165$, depending on expected load of the rollers (see Fig. 3.).

\section{References}

Camso (2018) Conversion Track System. Brochure no. 1509_BrochureAG_CTS_EN_europeV6, available online: https://camso.co/content/files/products/AG/1507_BrochureCTS_EN_RGB_NA_170127_161920.pdf.

Dudziński, P., Chołodowski, J. (2016) Energy efficiency of rubber tracked chassis. Journal of KONES, vol. 23, no. 2, pp. 97-104.

Dudziński, P., Chołodowski, J. (2017) On internal resistance of rubber track systems. in: Proc. of the 19th International \& 14th European-African Regional Conf. of the ISTVS (eds. Kiss, P., Mathe, L. and Farkas, C.), ISTVS, Budapest, pp. 1-14.

Dudziński, P., Ketting, M. (1996) New Ideas for Mobile Track Systems with Elastomer Belt Pt. 2.: Hybrid Friction/Positive Drive and Adjustable Belt Tension, in: Off-Road Machines and Vehicles in Theory and Practice, Proc. of the 1st International Conf. (eds. Dudziński, P., Hawrylak, H., Hohl, G., Ketting, M.,). ISTVS, Wrocław, pp. 131-138.

Dudziński, P., Ketting, M., Kosiara, A. (2003) Problems of tracked industrial vehicles suspension design. Transport Przemysłowy, no. 3/2003, pp. 58-63. (in Polish)

Dudziński, P., Kosiara, A., Konieczny, A. (2012) Virtual prototyping of a new generation undercarriage with rubber tracks for arctic applications. Postępy Nauki i Techniki, no. 14, pp. 64-74. (in Polish)

Dudziński, P. Gładysiewicz, A. (2007) Influence of pressure distribution between tracks and the ground on tractive properties of tracked vehicles. Transport Przemysłowy, no. 3/2007, pp. 72-76. (in Polish)

Dudziński P., Stefanow D. (2016) The Influence of Dynamic Soil Parametres on Tractive Performance of Off-Road Undercarriages. Journal of KONES, vol. 23, no. 3, pp. 115-120.

Kosiara, A., Stefanow, D. (2017) Development and validation of a system for monitoring of tip over stability of a single bucket excavator. in: Proc. of the 19th International \& 14th European-African Regional Conf. of the ISTVS (eds. Kiss, P., Mathe, L. and Farkas, C.), ISTVS, Budapest, pp. 1-14.

Rosenboom, L. (2008) Track assembly with idler wheels and cart incorporating same. US Patent no. 7.380.892.

Roth, T.A. (2004) Double-axis oscillating bogie wheels. US Patent no. US 6.712.549. 